\title{
Effect of turbulence on the energetics of foraging in Atlantic cod Gadus morhua larvae
}

\author{
Peter S. Galbraith ${ }^{1, *}$, Howard I. Browman ${ }^{2}$, Roberto G. Racca ${ }^{3}$, \\ Anne Berit Skiftesvik ${ }^{2}$, Jean-François Saint-Pierre ${ }^{1}$ \\ ${ }^{1}$ Ocean Sciences Branch, Maurice Lamontagne Institute, Department of Fisheries and Oceans Canada, 850 Route de la Mer, \\ PO Box 1000, Mont-Joli, Quebec G5H 3Z4, Canada \\ ${ }^{2}$ Institute of Marine Research-Austevoll, 5392 Storebø, Norway \\ ${ }^{3}$ JASCO Research Ltd, 2101-4464 Markham Street, Victoria, British Columbia V8Z 7X8, Canada
}

\begin{abstract}
A net energy gain (NEG) model was used to assess the effects of turbulence on the energy budget of Atlantic cod Gadus morhua larvae, feeding on copepod nauplii at different concentrations. The geometry of their prey search space was parameterised as either a sphere, hemisphere (the most commonly applied in analogous studies), or wedge. Observed distributions in behaviour (e.g. move duration, pause duration, turn angles) were used as model input, and 2 facets of this behaviour (move duration and move speed) were varied to examine how parameterised changes in foraging behaviour can affect the NEG of the predator. At a prey concentration of $100 \mathrm{l}^{-1}$, and in static water, NEG is an order of magnitude higher for a hemispherical shape relative to a wedge-shaped search volume. This difference decreases with increasing prey concentration $\left(600 \mathrm{l}^{-1}\right)$, but always remains considerable. When parameterised turbulence was added, prey capture rates for a larva with a hemispherical search space increases 3 times as much as for a larva with a wedge-shaped search space (typically a $50 \%$ increase using the hemisphere vs $15 \%$ using a wedge). Thus, when this one key assumption (the search volume shape) of current turbulence-effects models is more realistically parameterised, the theorized advantage of turbulence is greatly reduced (at the level of the animal's prey capture and NEG). This result demonstrates the need to carefully reassess the underlying assumptions of current turbulence-effects models and, therefore, the conclusions that have been based upon those models. Our NEG model also demonstrates the energetic benefits of certain changes in larval behaviour — such as shorter move durations - which lead to a more thorough and cost-effective search of the surrounding water for larvae with a wedge-shaped search volume. This latter effect is not observed for predators with spherical or hemispherical search volumes. These results indicate that it would be prudent to reconsider the conclusions of any previous study that was based upon over-simplified search space geometries.
\end{abstract}

KEY WORDS: Fish larvae $\cdot$ Prey search behaviour $\cdot$ Simulation model $\cdot$ Ichthyoplankton-zooplankton interaction $\cdot$ Encounter rate $\cdot$ Feeding rate $\cdot$ Net energy gain

Resale or republication not permitted without written consent of the publisher

\section{INTRODUCTION}

Since Rothschild \& Osborn (1988) theorized about how turbulence could impact the encounter rates between planktonic predators and their prey, that possibility has been widely studied (Dower et al. 1997, MacKenzie 2000, 2002). Despite this effort, neither field nor laboratory results have yet to strongly, consis- tently and unequivocally support the theory. MacKenzie \& Kiørboe (2000) speculated that this was due to the confounding interaction of the positive and negative effects of turbulence, and focused on the negative effect of turbulence on the success (or lack thereof) of prey pursuit. MacKenzie (2000) further argued that the lack of field observations clearly linking turbulence to feeding, growth and mortality in fish larvae was due to 
our lack of understanding of how some key interrelated components respond to turbulence. More recently, Reiss et al. (2002) combined in situ turbulence measurements made using shear-probe microstructure instruments with data on the vertical distribution of silver hake Merluccius bilinearis.

They compared feeding success under various levels of turbulence with encounter rate predictions based upon Kiørboe \& MacKenzie's (1995) formulation, which is a derivative of Rothschild \& Osborn (1988). Their analysis did not support the relationship between turbulence and feeding success predicted by the prevailing theory. Further, Franks (2001) argues that the spatial and temporal scales applied in field studies of larval fish feeding rates in situ are inadequate to resolve whether the relationships observed result from either (1) turbulence having directly increased the encounter rate between predator and prey particles or, (2) turbulence having indirectly increased them by causing the larvae and their prey to move out of turbulent waters and aggregate together, thereby increasing contact rates.

In a Comment Section devoted to turbulence encounter rate theory, several of the (controversial) assumptions were identified and discussed (Browman 1996). These included how turbulence energy spectra in the seas compared with those generated in the laboratory (or in simulation models), as well as several aspects of predator and prey behaviour that might be affected by turbulence and/or affect the outcome of models designed to evaluate turbulence effects (see below). Some of these were also taken up by Dower et al. (1997). Although it was concluded that changing any of these assumptions could alter the predictions of the theory, few evaluations of this possibility have been undertaken. Thus, in this study, we attempted to assess how changing the manner in which 2 key elements of turbulence encounter models (search volume geometry and the movement pattern associated with prey search) are parameterised - might lead to different conclusions. The basis for our focus on these particular aspects of the theory follows.

Rothschild \& Osborn (1988)'s turbulence encounter rate equation assumes that the geometry of the water volume searched by a predator is spherical. A more recent formulation by Kiørboe \& MacKenzie (1995) assumes that the search volume is a forward-projected hemisphere. The latter was used by MacKenzie \& Kiørboe (1995), by Reiss et al. (2002), as well as in a net energy gain (NEG) model reported upon by Pitchford et al. (2003). However, for all fish larvae for which such information exists (including the species studied by the preceding authors), the geometry of the visual perceptual field is neither a sphere nor a hemisphere, but more closely resembles a hemi-ellipse or wedge, pro- jecting mostly above the animal's body axis (Rosenthal 1969, Rosenthal \& Hempel 1970, O'Brien et al. 1989, Browman et al. 1990, Browman \& O'Brien 1992b). The effect of a smaller perceptual field on predator-prey encounter rates in turbulent conditions was recently examined by Lewis (2003) for cruise searching copepods. He concludes that the optimal swimming strategy (associated with prey search) under turbulent conditions for predators with perceptual fields that are more limited than perfectly symmetrical spheres or hemispheres differs radically from what is otherwise predicted. Therefore, it is likely that the analogous predictions for pause-travel fish larvae will also be different if the more realistic wedge-shaped search volume is applied instead of the 'traditional' sphere or hemisphere.

Turbulence apparently affects predator-prey encounter rates in a manner that is different for cruise and pause-travel predators (MacKenzie \& Kiørboe 1995). This difference is related to the characterization of cruising predators as searching for prey while moving, and to pause-travel predators as searching for prey only while stationary or, at least, not while actively swimming (see O'Brien et al. 1990). Following from the different movement patterns associated with these 2 prey search modes, Anderson et al. (1997) and Kramer \& McLaughlin (2001) identified differences in the energetic demands of foraging for pause-travel vs. cruise searchers. In assessing the effects of turbulence on the feeding rates of marine fish larvae, earlier studies have used Atlantic herring Clupea harengus as a representative cruise searcher. However, detailed observations of the swimming pattern exhibited by herring larvae while searching for prey, and the reported distribution of prey locations throughout the visual perceptual field (and not only at the periphery), do not support a cruise searcher categorization (Rosenthal 1969, Rosenthal \& Hempel 1970). Rather, those observations are more consistent with a pause-travel characterization. With the possible exception of clownfish Amphiprion perideraion (Coughlin et al. 1992), the few fish larvae for which prey search patterns have been characterized all appear to be pause-travel searchers (see Browman \& O'Brien 1992a,b). Therefore, in addition to search volume geometry, the work that we report upon here assesses how turbulence affects predator-prey encounter rates when several aspects of the swim pattern of a pause-travel searching fish larva are altered.

Following from the above, it appears prudent to reexamine the validity of the prevailing theory, and of the assumptions that are made in deriving it. Towards this end, we herein evaluate how the choice of geometry and volume for the predator's prey field affects the net energy gained by pause-travel searching Atlantic cod Gadus morhua larvae feeding on different concentrations of Calanus finmarchicus nauplii. The addition 
of simply parameterised turbulence is also examined in the context of different prey field geometry and volume. The results are extended to examine the effect of possible changes in behaviour on the NEG.

\section{MATERIALS AND METHODS}

Laboratory methods. Silhouette (shadow) video photography (SVP) was used to observe the behaviour of cod larvae. Our SVP system consists of 2 orthogonally-oriented optical rails, with the test aquarium $(20 \times 20 \times 20 \mathrm{~cm})$ placed at their intersection. The synchronously-recorded orthogonal views allows exact determination of the 3 dimensional positions of targets (larvae and/or their prey) which appear in both fields of view simultaneously. The outermost $5 \mathrm{~cm}$ of the aquarium walls were covered with black plastic (matte-surface) contact paper. This restricted the field of view to the central volume of water and ensured that the behaviours observed were not influenced by surface or edge effects; only cod larvae freely swimming in the water column were imaged, and their displacements analyzed. Complete descriptions of this equipment, the software used to extract the behavioural data (see below), and the rearing techniques applied to cod larvae, are presented in Browman et al. (2003).

Cod larvae from a single male-female cross and egg batch were collected from rearing tanks at $28 \mathrm{~d}$ posthatch and transferred to the SVP test aquarium where they were allowed to acclimate for at least $30 \mathrm{~min}$. Larvae were observed feeding on Calanus finmarchicus nauplii (their natural prey in the wild) at concentrations of 10,100 and 600 prey $\mathrm{l}^{-1}$ in static water conditions. Two replicate 30 min observation periods (with 40 different larvae, in a different aquarium, for each replicate) were video-taped for each naupliar concentration. Five min of these video-taped experiments, drawn from the middle of the 30 min observation period, were analyzed using custom software. The swim paths of cod larvae were analyzed for number and durations of stops (non-active displacement, as defined and operationalized by Collins et al. 1995), lengths and durations of moves, swim speed, and turn angles (separated into vertical and horizontal components). The frequency distributions (FDs) of these variables were computed, with bin sizes chosen based upon the observed ranges in the raw data. Using these FDs, as opposed to collapsing all of the data into a central tendency value ( \pm an error estimate), retains far more information about variability in behavioural responses and, therefore, provides a strong basis for modeling and statistical analyses (see below). For each prey concentrtion and replicate, all paths longer than $40 \mathrm{~mm}$ were pooled. A total of 10 paths $(2.88 \mathrm{~m}$ in total length) were used for prey concentrations of $10 \mathrm{l}^{-1}$, 8 paths totaling $1.74 \mathrm{~m}$ for $100 \mathrm{l}^{-1}$ and 10 paths totaling $2.06 \mathrm{~m}$ for $600 \mathrm{l}^{-1}$.

Model methods. A NEG model was applied to track the energy level gain (or loss) per unit time, $E_{l}$, of an individual pause-travel searching cod larva (of mass $M$ $=0.21 \mathrm{mg}$, corresponding to the mean dry weight of the larvae whose behaviour was observed). The larva's energy expenditure is estimated by combining a basal energy cost $E_{\mathrm{b}}\left(1.08 \times 10^{-6} \mathrm{cal} \mathrm{mg}^{-1} \mathrm{~s}^{-1}\right.$ or $4.52 \times 10^{-3}$ $\left.\mathrm{J} \mathrm{g}^{-1} \mathrm{~s}^{-1}\right)$ and a cost of moving (by swimming) $E_{\mathrm{m}}(2.73 \times$

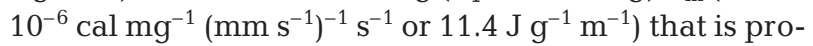
portional to move speed $V$. The origin of these metabolic rate values is discussed below. The larva gains energy by consuming a number $(C)$ of prey per unit time, each of energy content $E_{\mathrm{p}}=1.97 \times 10^{-3} \mathrm{cal}$ per capture, or $8.2 \mathrm{~mJ}$ (the energy content of a single Calanus finmarchicus nauplius). This can be expressed in Eq. 1, where $V$ is zero during pauses in swimming.

$$
E_{\mathrm{l}}=E_{\mathrm{p}} C-\left(E_{\mathrm{b}}+E_{\mathrm{m}} V\right) M
$$

Note that the energetic cost terms in the equation are proportional to larval mass. The qualitative results presented later in this work are not critically dependent upon this parameter. All model runs reported here were also carried out using $M=0.06 \mathrm{mg}$ (3.5 times lighter larvae) - qualitatively, the results and conclusions were consistent.

At each iterative step of the model, a random combination of 3-dimensional repositioning turn angles, move and pause durations are selected from the observed FDs for corresponding prey concentrations (Fig. 1). This is applied in a statistically proportional manner that forces the modelled FDs to conform to those observed. At each iteration, the larva moves and its energy consumption is calculated and placed into the 'expended' category. When the larva arrives at its new position, it searches for prey in a spherical, hemispherical, or wedge-shaped search space. Based upon our observations of prey location distances and angles in cod larvae (H. Browman unpubl. data), a $10 \mathrm{~mm}$ radius was chosen for the various search volume geometries. For the wedge-shaped search volume (which applies to cod larvae), a horizontal half-angle of $45^{\circ}$, a vertical half-angle of $10^{\circ}$, and radius of $10 \mathrm{~mm}$ (for a search volume of $181.8 \mathrm{~mm}^{3}$ or $1 / 23$ of the volume of a sphere of the same radius) were applied. The model calculates the spatial extent and volume of the new search space (dependent upon the geometry being simulated in that particular model run), which the simulated larva then scans for prey, excluding any part of the volume that was searched during the previous iteration. In this scenario, a search volume overlap between successive repositioning moves reduces the probability of finding prey (O'Brien et al. 1989, 1990). 

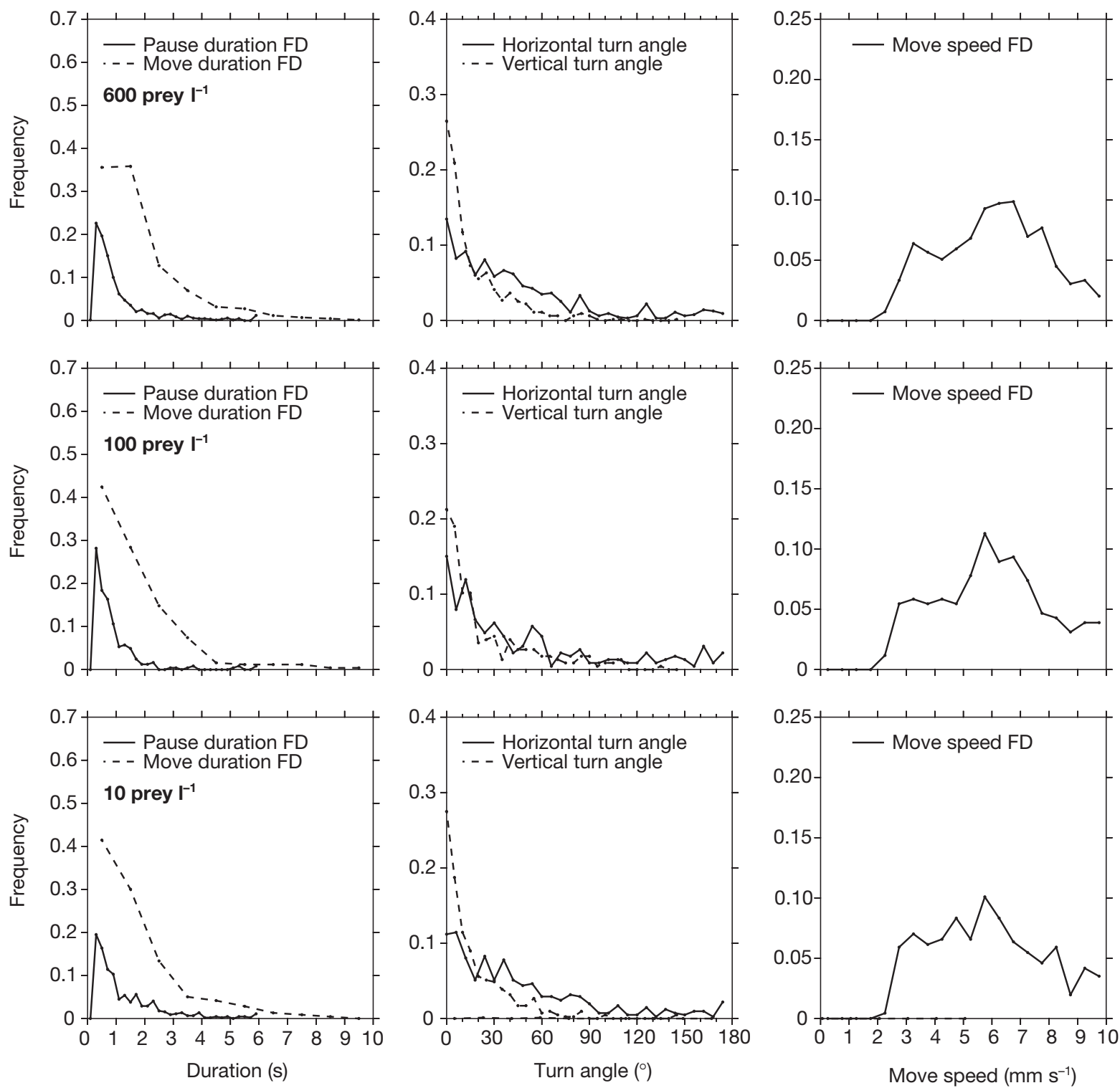

Fig. 1. Gadus morhua. Frequency distributions of the variables extracted from the swim paths of $28 \mathrm{~d}$ post-hatch Atlantic cod larvae foraging on Calanus finmarchicus nauplii at 3 concentrations. Pause and move durations are presented in the left-hand panels, horizontal and vertical turn angles in the middle panels, and move speeds in the right-hand panels

The prey are randomly distributed and are not moving. If the search volume contains 1 or more prey, the likelihood of successfully finding one is expressed as an exponential function such as used elsewhere in the fish foraging literature (e.g. O'Brien et al. 1989):

$$
L P=\left(1-\mathrm{e}^{-a}\right)
$$

where $L P$ is the Location Probability and $a$ is the visual abundance, obtained by multiplying the mean prey concentration by the search volume. When the visual abundance is very small, as for a wedge-shaped search volume (for our highest value of 600 prey $^{-1}, a=0.109$ and is, therefore, much less than unity), this expression reduces to $L P \approx a$, e.g. the likelihood of successfully finding prey is approximately equal to the visual abundance $(L P=0.103$ for $a=0.109)$. Table 1 shows the wide range of $a$ (expressed as the inverse, 1/a) for each of the search volume geometries at all 3 prey concentrations. This is perhaps the single greatest difference affecting NEG between the 3 geometries: many iterations are always required in order to find prey when a wedge is applied, but predators able to search a complete sphere would be almost saturated with prey even at prey concentrations of 100 prey $\mathrm{l}^{-1}$. 
If a prey is located, it is assumed to be within the portion of the search volume that had no overlap with the previous iteration (since it was not found then), and a random location within that part of the search volume is selected as the prey position. The larvae moves to this position at a prey pursuit speed of $2 \mathrm{~mm} \mathrm{~s}^{-1}(\mathrm{H}$. Browman unpubl. data), expending the required amount of time and energy to get there. The energy of the larva is increased by the calorific content of 1 Calanus finmarchicus nauplius (as above). A 100\% capture, retention, and energy assimilation efficiency is assumed. Although this is not realistic, as long as the same assumption is applied to all modelled scenarios, it still allows for a meaningful evaluation of relative effects. After a modelling run of 5000 s, a summary table that includes the number of prey consumed, the mean search volume overlap, and the net energy gained (or lost) is produced.

To simulate the effect of turbulence on search volume overlap, and the concomitant effects on encounterrates, an advective velocity of $5 \mathrm{~mm} \mathrm{~s}^{-1}$ was added to the predator (but not to the prey; see below) in a different random direction at every pause-travel cycle. This simplified parameterisation is similar to that applied by Fiksen \& MacKenzie (2002). Thus, half of the model runs were in 'static' water, while the other half had this advective velocity added to the predator's move speed (with no attributed energy cost), to simulate advection by a turbulent field. Using this approach, the manner in which advective transport from the turbulent flow reduces search volume overlap between consecutive searches could be assessed.

Critique of model methods. A discussion of the simplifications and assumptions that are made in our simulation model, and of the limitations that these impose upon the interpretations that issue from our results, follows.

Metabolic rates: The energy expenditure values used here are drawn from microrespirometry measurements made by von Herbing \& Boutilier (1996) on resting and swimming cod larvae. The relationship between move cost and swim speed was best fit by a linear regression of the metabolic rates against swimming speeds for data gathered during the first $40 \mathrm{~d}$ of cod larval life (most of the swim speed variance is from the exogenous feeding period, > $14 \mathrm{~d}$ post-hatch at $5^{\circ} \mathrm{C}$ ). This linear relationship implies that the timeintegrated energetic cost of moving is proportional to the distance travelled, with no influence of swim speed (i.e. a larva expends the same energy swimming a certain distance slowly as it does swimming fast, only taking longer to do so). Although this might be approximately correct for small and typical ranges of move speeds, it is also counterintuitive. Consider that Stokes'
Table 1. Gadus morhua. Comparison of the volume of water contained in search spaces of different geometry for Atlantic cod larvae. The values in each prey concentration column are the number of complete search volumes (or search iterations) required (probabilistically) to find a single prey (assuming that there is no overlap between volumes searched in successive iterations). This number is $1 / a$ where $a$ is the visual abundance

\begin{tabular}{|c|c|c|c|c|}
\hline \multirow[t]{2}{*}{ Prey conc. } & \multirow[t]{2}{*}{ Volume } & \multicolumn{3}{|c|}{$\begin{array}{l}\text { Complete search volumes } \\
\text { per prey }(1 / a)\end{array}$} \\
\hline & & 10 prey l$^{-1}$ & 100 prey $\mathrm{l}^{-1}$ & 600 prey $\mathrm{l}^{-1}$ \\
\hline Sphere & V & 23.9 & 2.4 & 0.4 \\
\hline Hemisphere & $\mathrm{V} / 2$ & 47.8 & 4.8 & 0.8 \\
\hline Wedge & V/23 & 550.5 & 55.1 & 9.2 \\
\hline
\end{tabular}

Law (as applied in the Pitchford et al. (2003) NEG model) in which the drag of laminar flow around a sphere is proportional to velocity, making the power expended during swimming proportional to velocity squared. Applying the Stokes relation with typical parameter values (a radius of $5 \mathrm{~mm}$ and a velocity of 6 $\mathrm{mm} \mathrm{s}^{-1}$ ) yields a theoretical cost of moving that is 1000 times smaller than those measured by von Herbing \& Boutilier (1996). This implies that the physiological overhead for a small larva swimming in relatively cold water is overwhelming compared to viscous stress alone. Thus, using the Stokes formulation without applying any physiological overhead would yield predictions of much too high optimal move speeds, which is exactly what Pitchford et al. (2003) reported: the optimal speeds that they calculated for herring larvae were on the order of 12 body lengths $\mathrm{s}^{-1}$, whereas our typical observations of swim speed are on the order of 1 body length $\mathrm{s}^{-1}$.

The cost of moves $E_{\mathrm{m}}$ used here $\left(2.73 \times 10^{-6} \mathrm{cal} \mathrm{mg}^{-1}\right.$ $\left[\mathrm{mm} \mathrm{s}^{-1}\right]^{-1} \mathrm{~s}^{-1}$ ) corresponds to an integrated value of $11.4 \mathrm{~J} \mathrm{~g}^{-1} \mathrm{~m}^{-1}$. In more recent work, the metabolic cost of transport is reported as 50 and $70 \mathrm{~J} \mathrm{~g}^{-1} \mathrm{~m}^{-1}$ for cod larvae at 5 and $10^{\circ} \mathrm{C}$ respectively (von Herbing 2002, Fig. 2). All of this illustrates the uncertainty in estimating this parameter. Thus, we have chosen to apply the conservative value initially reported by von Herbing \& Boutilier (1996). In any case, changing this will only affect the absolute values issued by the model, and not the interpretations, which are based upon comparisons of relative values.

The absolute values for NEG issued by our model must not be viewed as accurate indicators of the energy balance for foraging cod larvae-much more precise metabolic rates than are currently available will be required to achieve that.

Context for choosing to model only one level of turbulence: $100 \%$ prey capture, retention and assimilation efficiencies are assumed. However, it is possible 
that increased turbulence would decrease these percentages (e.g. MacKenzie \& Kiørboe 2000). Since no attempt is made to parameterise this effect, a decrease in NEG at high levels of turbulence cannot be predicted since only positive effects of turbulence are included in the model (via the turbulent flow-related reduction of search volume overlap during successive searches). Since we were only interested in assessing first-order effects of turbulence on the overlap in search volume between successive searches, there was little point in modelling a wide range of turbulent velocities. Thus, in addition to static water, only 1 turbulent velocity value was used.

Wind speed associated with the level of turbulence modelled: The $5 \mathrm{~mm} \mathrm{~s}^{-1}$ turbulent velocity applied in the model can be roughly converted to a turbulence intensity, $\varepsilon$, using Kolmogorov scaling:

$$
W=1.9(\varepsilon l)^{1 / 3}
$$

where $l$ is the turbulent length-scale, chosen here to be the length of the search volume, $10 \mathrm{~mm}$, and the constant 1.9 was used by Rothschild \& Osborn (1988). The turbulent velocity of $5 \mathrm{~mm} \mathrm{~s}^{-1}$ corresponds to $\varepsilon=1.8 \times$ $10^{-6} \mathrm{~m}^{2} \mathrm{~s}^{-3}$.

Several additional assumptions are required to predict the wind strength that would force this turbulent intensity in the surface layer of the ocean. Oakey \& Elliot (1982) measured approximately $1 \%$ of the work done by wind stress below a height of $10 \mathrm{~m}, E_{10}$, as dissipation of turbulent kinetic energy, where $E_{10}$ is:

$$
E_{10}=\rho_{\mathrm{a}} C_{10} U_{10}{ }^{3}
$$

and $\rho_{\mathrm{a}}$ is the density of air $\left(\approx 1.2 \mathrm{~kg} \mathrm{~m}^{-3}\right), C_{10}$ is a drag coefficient $\left(1.3 \times 10^{-3}\right)$ and $U_{10}$ is the wind speed measured at a height of $10 \mathrm{~m}$. Assuming that this $1 \%$ of the wind energy is dissipated in the top $20 \mathrm{~m}$ of the water column, the wind speed required to yield $1.8 \times 10^{-6} \mathrm{~m}^{2} \mathrm{~s}^{-3}$ is $13.2 \mathrm{~m} \mathrm{~s}^{-1}$ or 25.7 knots. Therefore, the $5 \mathrm{~mm} \mathrm{~s}^{-1}$ turbulent velocity applied in our model runs corresponds to fairly strong ocean surface turbulence.

Possible role of advective and vorticity effects not considered in the model: The simplified parameterisation of turbulence applied in our model probably underestimates the degree to which turbulence decreases the overlap between search volumes at successive moves. One reason is that we do not address the possible effect associated with the advection of prey-caused by the fluid strain associated with turbulence-into the search volume during a pause. However, we consider this latter process less relevant, for the following reasons.

A pause-travel predator and, in fact, all fish larvae for which such data exist, scan for prey throughout the visual search space volume (Rosenthal 1969, Browman
\& O'Brien 1992b) and it is unclear if the predator would react to a prey item that is advecting through its search volume while it is being scanned for prey. Our detailed observations of prey search in the larvae of over 10 species of fish all demonstrate that, when a prey item is moving through the search volume, the larva does not actually attack it, even if it is perceived (Browman \& O'Brien 1992b, H. Browman \& A. Skiftesvik. unpubl. data). It is also possible that a prey item swept into the visual perceptual field would not be detected at all, having entered a previously scanned portion of the search volume, or that the prey item would pass out of the search volume before it was detected. Furthermore, generally prey items will be advected out of the search volume as often as they are advected in, yielding a marginal net effect. Two simple scalings further support our contention that the advection effect is minimal. First, since the pause duration (i.e. the search time) is typically a third of the move duration (i.e. the non-search time) (Fig. 1), the advection effect will be smaller (by the same proportion) than the effect of turbulence on search volume overlap. The advection effect could possibly become more important if the behaviour of the larvae is modified towards shorter move durations and/or longer pause durations in the presence of turbulence. However, there exists no empirical evidence to support this. Second, at turbulent velocities of $5 \mathrm{~mm} \mathrm{~s}^{-1}$ it would take approximately $2 \mathrm{~s}$ for the advection effect to flush a cod larva's search volume. Since the pause duration (i.e. the search time) is typically a quarter of that value, there is a low probability of advection moving a prey particle into the search space while the larva is scanning (and even then, as stated above, it might not be perceived).

Only a $5 \mathrm{~mm} \mathrm{~s}^{-1}$ random advection was modelled, but real turbulence would also result in some degree of rotation in the predator's orientation. This effect is more important to smaller organisms because the vorticity in a turbulent flow increases at progressively smaller scales until the effects of viscosity appear. In fact, Maar et al. (2003) identified this as a limitation for zooplankton that encounter a turbulence-induced rate of rotation that they cannot swim against (at some high level of turbulence). For fish larvae, the following line of reasoning indicates that it might be beneficial.

The turbulent shear spectra is maximal at (small) turbulent length scales where viscosity begins to dampen it out. This transition to a viscocity-dominated regime is typically said to occur at about 3 to 4 times $2 \pi L_{\mathrm{K}}$ (e.g. Gargett 1997), where $L_{\mathrm{K}}$ is the Kolmogorov length scale $\left(v^{3} \varepsilon^{-1}\right)^{1 / 4}=0.86 \mathrm{~mm}$ in the case of our model (although Hill et al. 1992 argue that the transition to a viscocity-dominated regime occurs at a smaller scale). The transition at 3 to 4 times $2 \pi L_{\mathrm{K}}$ occurs at about 16 to $21 \mathrm{~mm}$ at the (high) turbulence level that we applied, 
$\varepsilon=1.8 \times 10^{-6} \mathrm{~m}^{2} \mathrm{~s}^{-3}$, where the shear is approximately $\left(\varepsilon v^{-1}\right)^{1 / 2}=1.3$, corresponding to a rotation rate of $0.67 \mathrm{rad} \mathrm{s}^{-1}$, or about $40^{\circ} \mathrm{s}^{-1}$ (half of the vorticity). Since the cod larvae that we modelled are smaller $(6 \mathrm{~mm})$ than 16 to $21 \mathrm{~mm}$, they experience a laminar viscous shear with the same rotation rate (since the scale is smaller than the inertial-subrange).

Since the mean pause duration is of the order of $0.45 \mathrm{~s}$ (see Fig. 1), the rotation associated with vorticity during the pause duration is similar to the mean vertical turn angle (between 19 and $27^{\circ}$, depending upon prey concentration) and less than half the mean horizontal turn angle (between 47 and $52^{\circ}$ for all prey concentrations). It must be noted that this extra rotation does not necessarily lead to a decrease in search volume overlap, as $50 \%$ of the random turbulence-added rotation could be in opposition to the larvae's own turn angles and, thereby, reduce their effect.

In summary, by omitting the effect of vorticity, the overlap in search volumes between successive moves is somewhat overestimated by the model, but to a small and unquantified degree. However, this effect is less important at levels of turbulence lower than that applied here since shear is proportional to $\varepsilon^{1 / 2}$.

Final caveats: Not all assumptions made under the simplified parameterisation of turbulence applied here lead to decreased modelled encounter rates compared to using real turbulence. The parameterisation can also increase the perceived effect on search volume overlap, since the advective velocity of $5 \mathrm{~mm} \mathrm{~s}^{-1}$ is applied to the predator only, but in reality some of the nearby water will be carried along in the viscous flow found at these small scales.

All of the above explicitly recognises the trade-offs associated with any such modelling exercise. It also identifies the level of uncertainty surrounding most of the variables that must be parameterised in such models. Nonetheless, all else being equal, the approach still has merit as a tool that can be used to explore the relative effects of turbulence on search volume overlap and predator behaviour.

\section{RESULTS AND DISCUSSION}

\section{Effect of search volume geometry and turbulence on NEG}

Turbulence is expected to affect the NEG of feeding predators in at least 2 (possibly interactive) ways: (1) Through changes in the predator's behaviour that affect its energy expenditure and/or, (2) through changes in search volume overlap between successive predator moves by the turbulent flow which, in turn, change the encounter rates between predator and prey. In this section, only the latter will be addressed. The effects of changes in behaviour will be parameterised in a later section.

The NEG model was run 10 times for each of 3 sets of FDs generated from behavioural observations of cod larvae foraging at 3 prey concentrations (10, 100 and 600 prey $\mathrm{l}^{-1}$ ). The model was run in this manner for a wedge-shaped search volume, and again using a hemispherical, and then a spherical search volume. This entire series of model runs was repeated with a single simulated turbulent velocity added. The resulting NEG values are presented in Fig. 2 using whisker plots to illustrate variability among the 10 'replicate' runs.
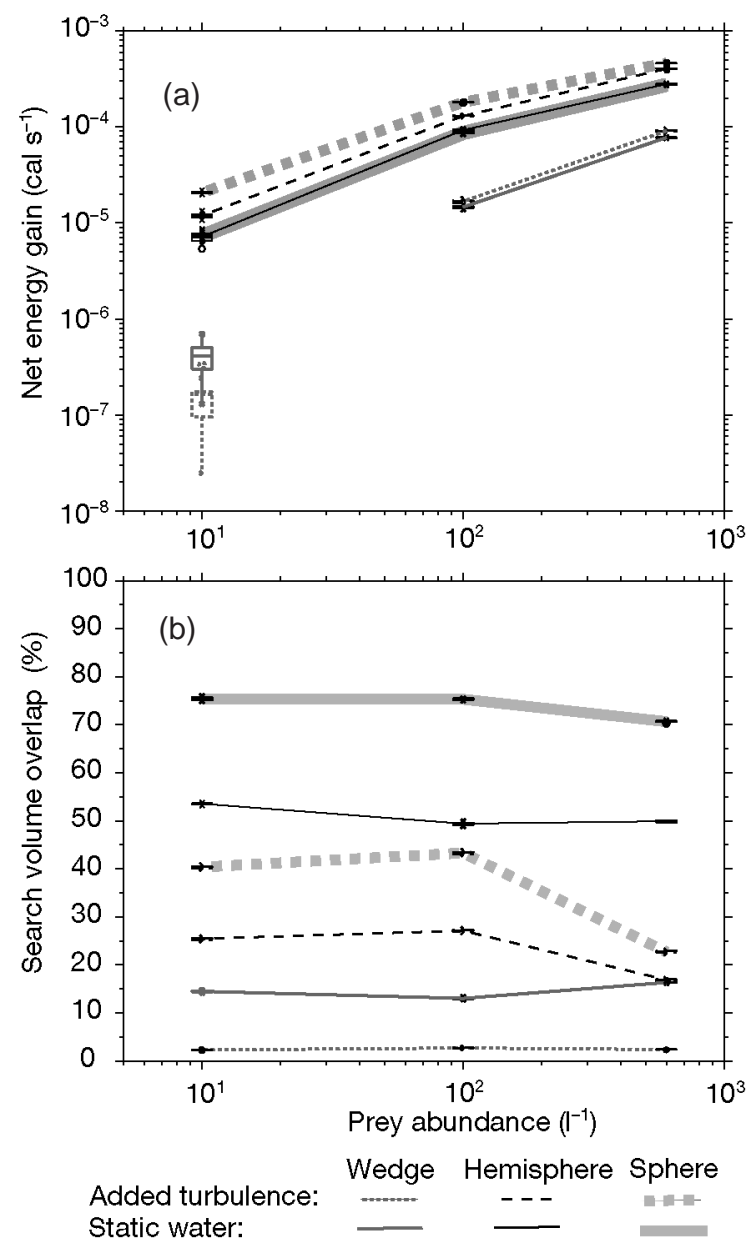

Fig. 2. Gadus morhua. (a) Net energy gain, NEG, and (b) search volume overlap for $28 \mathrm{~d}$ post-hatch Atlantic cod larvae foraging on Calanus finmarchicus nauplii at 3 concentrations. Results are from 180 model runs, 10 each for prey concentra-

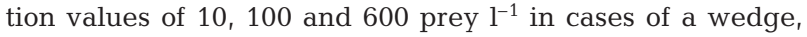
hemisphere and a sphere shaped search volumes. These were modelled in static water (solid lines) as well as with $5 \mathrm{~mm} \mathrm{~s}^{-1}$ random velocity (dashed lines) simulating turbulence added. The wedge results for 10 prey $\mathrm{l}^{-1}$ are negative (energy loss). Note that in (a) the NEG results for the sphere and hemisphere in static water nearly overlap 
In either static or turbulent water, there is more than one order of magnitude difference in NEG between the wedge and sphere shapes at a prey concentration of $100 \mathrm{l}^{-1}$ (Fig. 2). The difference decreases with increasing prey concentration, but always remains considerable. The reduced effect at higher prey concentration is a result of the visual abundance, $a$, reach-

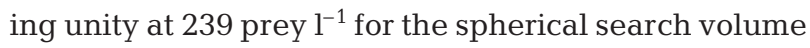
geometry. Therefore, increasing prey concentration beyond this value saturates the capture rate. The wedge shape has $1 / 23$ the volume of a sphere (or $1.818 \times$ $10^{-4} \mathrm{l}$ ) and would, therefore, require a very high prey concentration of 5516 prey $^{-1}$ in order to reach a visual abundance of 1 (the fraction of the sphere volume occupied by the wedge is $\theta \sin (\phi) / \pi$, where $\theta$ is the horizontal half-angle and $\phi$ is the vertical half-angle, both expressed in radians). Note that the NEG is slightly

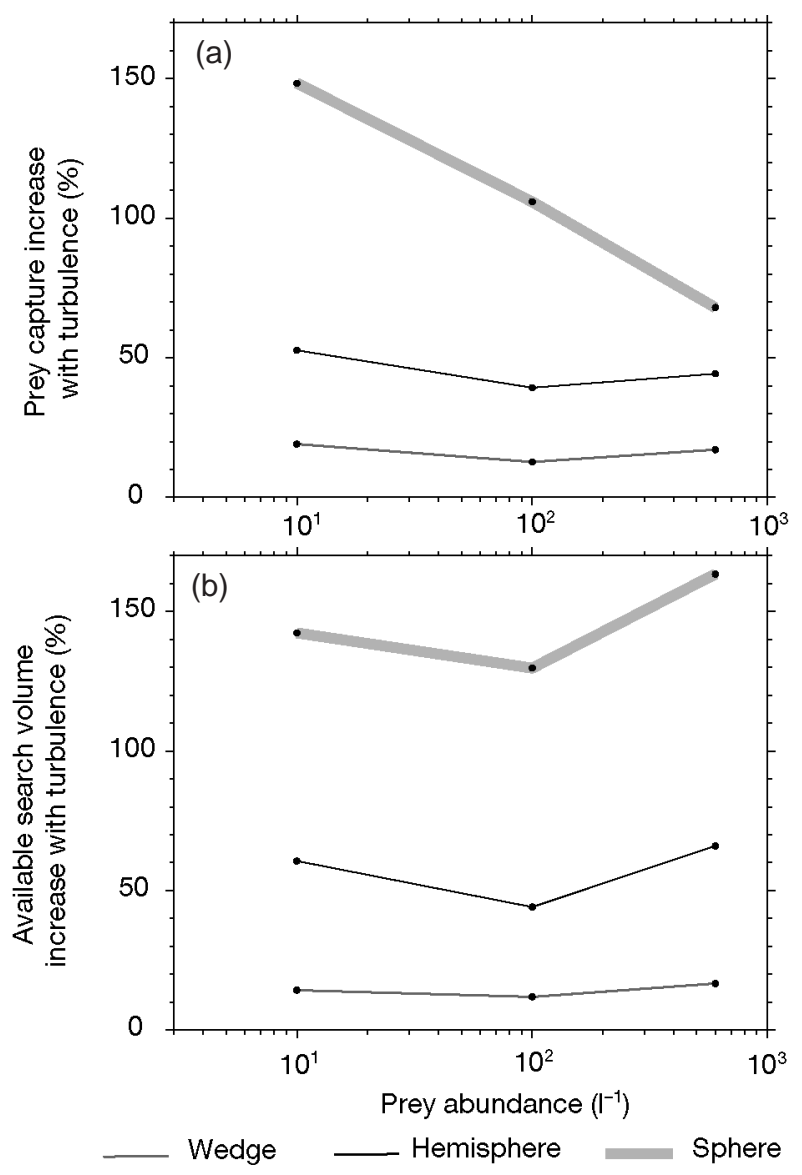

Fig. 3. Gadus morhua. Percent change in (a) prey captures and (b) new volume of water available to be searched for $28 \mathrm{~d}$ post-hatch Atlantic cod larvae foraging on Calanus finmarchicus nauplii at 3 concentrations and with a wedge, hemisphere or sphere shaped search volume. Results are from the same model runs as in Fig. 2. The values for model runs with turbulence added ( $5 \mathrm{~mm} \mathrm{~s}^{-1}$ random velocity) are presented as a percentage of those for static water negative for the wedge shape at the lowest prey concentration of $10 \mathrm{l}^{-1}$, whether turbulence is added or not; too few prey are found in the small search volume to offset metabolic energy costs (but recall that this should not be taken as indicative of the larva's 'true' energy balance).

In static water, the NEG results for the sphere and hemisphere are nearly identical, which is not surprising once search volume overlap is considered. While the spherical shape gives twice as large a prey location volume as the hemisphere, the mean search volume overlap between successive moves is 75 versus $54 \%$

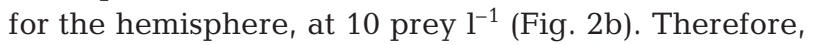
the volume of new water at each iteration is nearly the same for either case $(25 \% \times 2 \approx 46 \%)$. The wedge shape has a mean overlap of $15 \%$ in static water and $2.3 \%$ when turbulence is added, yielding only a modest increase in the volume of new water from 85 to $98 \%$. Thus, although the overlap is practically eliminated with the addition of turbulence, it is already quite small, even in static water. Thus, there is a much smaller increase in NEG for the wedge shape. These examples illustrate the importance of considering search volume overlap.

To more intuitively illustrate the different effect of turbulence on the 3 search volume geometries (at all 3 prey concentrations), these same model results are replotted in Fig. 3 to show capture rate increase. The percent increase in prey captures $(C)$ associated with added turbulence is much higher for the sphere and the hemisphere than it is for the wedge. As noted above, this results from the much smaller effect of turbulence (in decreasing search volume overlap) for a wedge relative to a sphere or hemisphere: there is always less overlap for a wedge, so turbulence can never have as pronounced an effect on this parameter.

Since they were derived from move and pause FDs - under the assumptions that search volumes are scanned for prey once during a pause and that turbulent shear has little effect during this time periodthese comparisons of prey capture rate are not dependent upon metabolic rates. As such, we view this as an important substantiation of those model outputs that are linked to metabolic rates.

In summary, the effect of turbulence on search volume overlap, prey capture, and NEG is much smaller when a realistic search space geometry (i.e. a wedge shape) is applied compared to a sphere or hemisphere. However, search volume overlap is not usually a significant feeding limitation with the wedge shape because, even in static water, only a small rotation of the larva (without any forward motion) is required to take the predator into previously unsearched water. Paradoxically, while the effect of turbulence is much smaller on the wedge shape, it may be of greater rela- 
tive importance than for the other 2 much larger search space geometries. This is so because the probability of finding prey during a pause event is so much lower for a wedge (as a result of its much smaller volume) than for the other shapes. Thus, for the wedge, even a small turbulence-related increase may be significant.

\section{Effect of turbulence-related behavioural changes on NEG}

In order to evaluate the effect that turbulencerelated changes in behaviour might have on NEG, FDs generated from observations made under turbulent conditions are required. However, the move speed, duration, distance and turn angle FDs used as input to our model were obtained in laboratory experiments made in static water. Therefore, we do not know (a priori) how turbulence affects the behaviour of larval fish predators, nor how those changes would affect the FDs although MacKenzie \& Kiørboe (1995) observed shorter pause durations in turbulent water than in static water.

To parameterise the range of possible effects, we skewed some of the static water FDs upwards and downwards. We did not include the turn angle FDs among those being altered because such a manipulation would only have a marginal effect.

If turn angles were to be influenced by the presence of turbulence, the probability of encountering prey could be affected to some extent by the change in overlap of the search volumes, but there would be no significant change in the energy expended by the predator. As discussed above, a variation in the turn angle FDs would influence search volume overlap only for the hemisphere and wedge shapes, and marginally so for the latter since the overlap is very small in the first place.

\section{Move duration}

We began by altering the FD of the factor that is easiest for the predator to change, and which also has a significant impact on its NEG i.e. the move (or swim) duration. We will examine the effect of altering move speed in a later section. However, move duration likely varies over a broader range than does speed. Since we do not know how the shape of the FDs would be affected by turbulence, we applied a scaling factor (to simulate a range of possible turbulence effects) by multiplying the FDs by numbers ranging from $1 / 30$ to 30 . For example, in static water, the FD for move duration had most of its values between 0 and $6 \mathrm{~s}$; in the scaled FDs these numbers are reduced to $1 / 30$ of the initial value ( 0 to $0.2 \mathrm{~s}$ ), and increased to as much as 30 times more (0 to $180 \mathrm{~s})$. This, in effect, extrapolates behaviour to unreachable conditions, since larvae are not expected to move 30 times longer before stopping to search for prey. This parameterisation will quantify the effects of behavioural changes whether they are caused by turbulence or not.

\section{Spherical search volume}

Fig. 4 shows the NEG and search volume overlap model results using a sphere search volume $(10 \mathrm{~mm}$ radius) for 3 prey concentrations (600, 100 and 10 prey $\mathrm{l}^{-1}$ ) as a function of the multiplication factor $x$ applied to the move duration FD. At $x=1$, the experimental
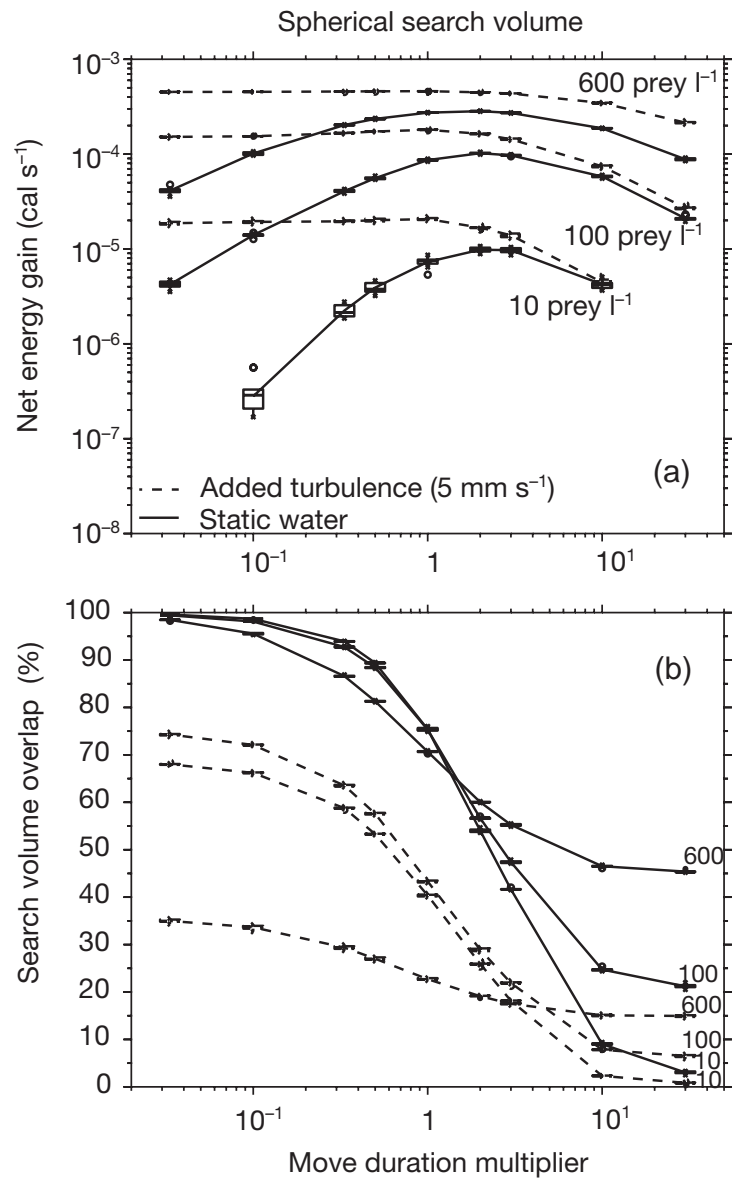

Fig. 4. Gadus morhua. (a) Net energy gain and (b) search volume overlap for $28 \mathrm{~d}$ post-hatch Atlantic cod larvae foraging on Calanus finmarchicus nauplii at 3 concentrations, with a spherical shaped search volume. The horizontal axis is the multiplication factor applied to the static water move duration FD, from $1 / 30$ as long to 30 times longer. Lines are the means for 10,100 and 600 prey $\mathrm{l}^{-1}$ in both cases of static water (solid lines) as well as with $5 \mathrm{~mm} \mathrm{~s}^{-1}$ turbulent velocity added (dashed lines) 
FDs derived in static water are used as model inputs to obtain the NEG results and coincide with values shown in Fig. 2; at lower and higher values of the $x$ multiplier, the FDs were artificially scaled by the amount shown. For each of 9 move duration FD multipliers, the model was run 10 times for both static conditions (solid lines) and with an added random velocity of $5 \mathrm{~mm} \mathrm{~s}^{-1}$ to parameterise turbulence (dashed lines), for a total of 540 model runs. NEG results at 10 prey $\mathrm{l}^{-1}$ are not shown for the lowest and highest FD rescalings because they were negative (net energy loss).

The NEG is most dependent on prey concentration, varying almost proportionally by orders of magnitude for prey concentrations from 10 to 100 to $600 \mathrm{l}^{-1}$. This results from the probability of encountering a prey, which increases linearly with prey concentration until becoming nearly saturated at the highest values.

In static conditions, the relation between NEG and move duration is dome-shaped, with a maximum at about twice the values observed in static water (i.e. near $x=2$ on Fig. 4). Beyond this maximum (for $x>2$ ), more energy is expended by moving than is offset by the increased probability of finding prey. Below the maximum, shorter move durations (for $x<2$ ) conserve energy, but this saving is insufficient to offset the lower probability of finding prey that results from the increasing overlap (close to $100 \%$ ) in search volumes between successive moves (Fig. 4b).

The effect of adding the parameterised $5 \mathrm{~mm} \mathrm{~s}^{-1}$ turbulence is seen in the dashed curves (Fig. 4). Turbulence greatly increases NEG at low move durations, thus eliminating the dome shape (Fig. 4a) by reducing the overlap in search volumes between pause-travel iterations at move duration multipliers less than unity (Fig. 4b). For a larva with a spherical search volume, move durations observed in static water are nearly optimal. Increasing (beyond 2) or lowering the move duration from static water values results in decreasing NEG.

The addition of turbulence enhances NEG by a factor of 2 (at 100 prey $\mathrm{l}^{-1}$ ) at normal move durations, which is a much smaller variation than results from changing prey concentration. However, the addition of turbulence allows a change in behaviour towards shorter move durations without significantly decreasing NEG. This is because the increased overlap between successive search volumes is mostly eliminated by the turbulent velocity that advects the predator into a previously unsearched parcel of water.

The degree of overlap between successive search volumes does not vary the same way for each of the prey concentrations in Fig. 4b. This is not caused by using different FDs for each concentration; qualitatively similar results (not shown) were obtained when using the same FD for all 3 prey concentrations. The different curves for the search overlap functions are actually caused by the high probability of finding prey using a spherical search volume at high prey concentrations and are possibly an artefact of the model. For example, making the predator move faster $(x>1$; Fig. 4b) considerably reduces search volume overlap at low prey concentrations because it travels further. However, at high prey concentrations, the predator is likely to find a prey in a single search event, and so the next search volume will occur in close proximity yielding a fairly high overlapping volume. This reflects the manner in which behaviour was incorporated into the model and, as such, is somewhat arbitrary. Nonetheless, NEG results should not be greatly affected if this were modified; qualitatively consistent results would be obtained.

Hemispherical search volume

Analogous runs of the model were undertaken using a hemispherical search volume; the most common shape used in analogous studies (Kiørboe \& MacKenzie 1995, MacKenzie \& Kiørboe 1995, Reiss et al. 2002, Pitchford et al. 2003). The variability in NEG across various move durations in simulated turbulence, shown in Fig. 5a (dashed lines), is qualitatively similar to that associated with a spherical search volume (Fig. 4a, dashed lines). However, the NEG in static water is very different: the dome shape of the relationship disappears (Fig. 5a, solid lines). This is because the search volume overlap remains fairly constant when the move duration multiplier is reduced (Fig. 5b), thanks to the overriding effect of predator re-orientation during pauses, as opposed to the situation for the spherical shape for which the overlap approaches $100 \%$ with reduced move duration multipliers (Fig. 4b, solid lines).

\section{Wedge-shaped search volume}

The model results for a wedge-shaped search volume are presented in Fig. 6. Only positive values of NEG are shown; the lines are cut off at the move duration multiplier for which the NEG became negative (e.g. for a prey concentration of $100 \mathrm{l}^{-1}$ any move duration multiplier greater than 3 leads to net energy loss, and NEG only becomes positive for prey concentration of $10 \mathrm{l}^{-1}$ at very low move duration multipliers). Increasing the prey concentration from low $\left(10 \mathrm{l}^{-1}\right)$ to high $\left(600 \mathrm{l}^{-1}\right)$ values extends the upper end of move durations at which NEG remains positive. At 100 to 600 prey $\mathrm{l}^{-1}$, all likely possible move duration distributions lead to positive NEG. The model runs with low 

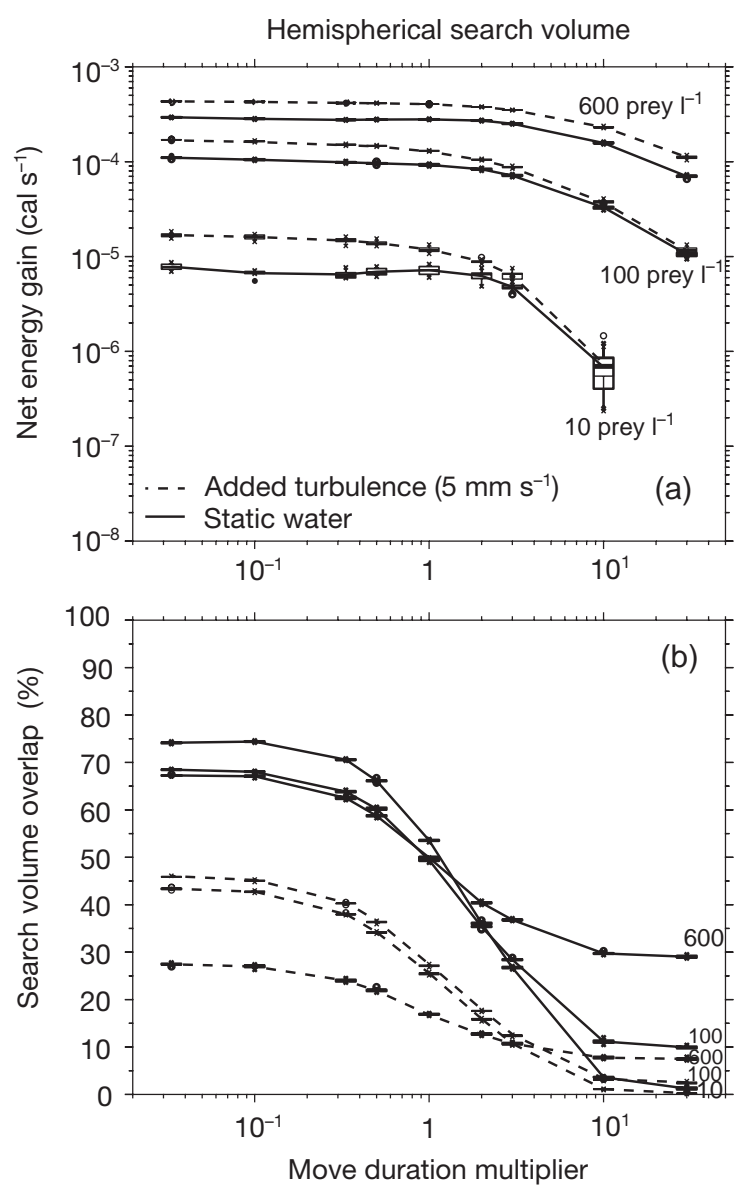

Fig. 5. Gadus morhua. (a) Net energy gain and (b) search volume overlap for $28 \mathrm{~d}$ post-hatch Atlantic cod larvae foraging on Calanus finmarchicus nauplii at 3 concentrations, with a hemispherical shaped search volume. The horizontal axis is the multiplication factor applied to the static water move duration $\mathrm{FD}$, from $1 / 30$ as long to 30 times longer. Lines are the means for 10, 100 and 600 prey $\mathrm{l}^{-1}$ in both cases of static water (solid lines) as well as with $5 \mathrm{~mm} \mathrm{~s}^{-1}$ turbulent velocity added (dashed lines)

prey concentrations (10 prey $\mathrm{l}^{-1}$ ) indicate that even a normal move speed distribution leads to negative NEG (again, recall that this should not be taken as anything more than a relative measure). Moreover, the model assumes a simplistic $100 \%$ capture rate (which is unrealistic, Munk (1995) obtained 22\% for hungry cod larvae). If capture rate were reduced, the NEG would become negative at even lower move speeds. It appears likely that the metabolic rates used in the model are somewhat high, although more recent microrespirometry measurements are even higher (von Herbing 2002). This highlights the need for more work on the energy budgets of fish larvae, particularly with respect to the cost of swimming.
Comparing these results to those obtained for a spherical search volume, the following differences are noted.

- There is no dome-shaped relationship. When the move duration is decreased $(x<1)$ less energy is spent moving and more time is spent searching. This leads to enhanced NEG because the larva performs an increased number of pause-travel events and, thereby, searches a greater volume of water for prey. In static water $(x=1)$, larvae spend $50 \%$ of the time searching, and the rest of the time moving (as gathered from full model results that are not shown). The model demonstrates that less time spent moving leads to a more efficient search of the predator's surroundings, and slightly increased NEG. Search volume overlap is not a significant problem for a wedge because only a small
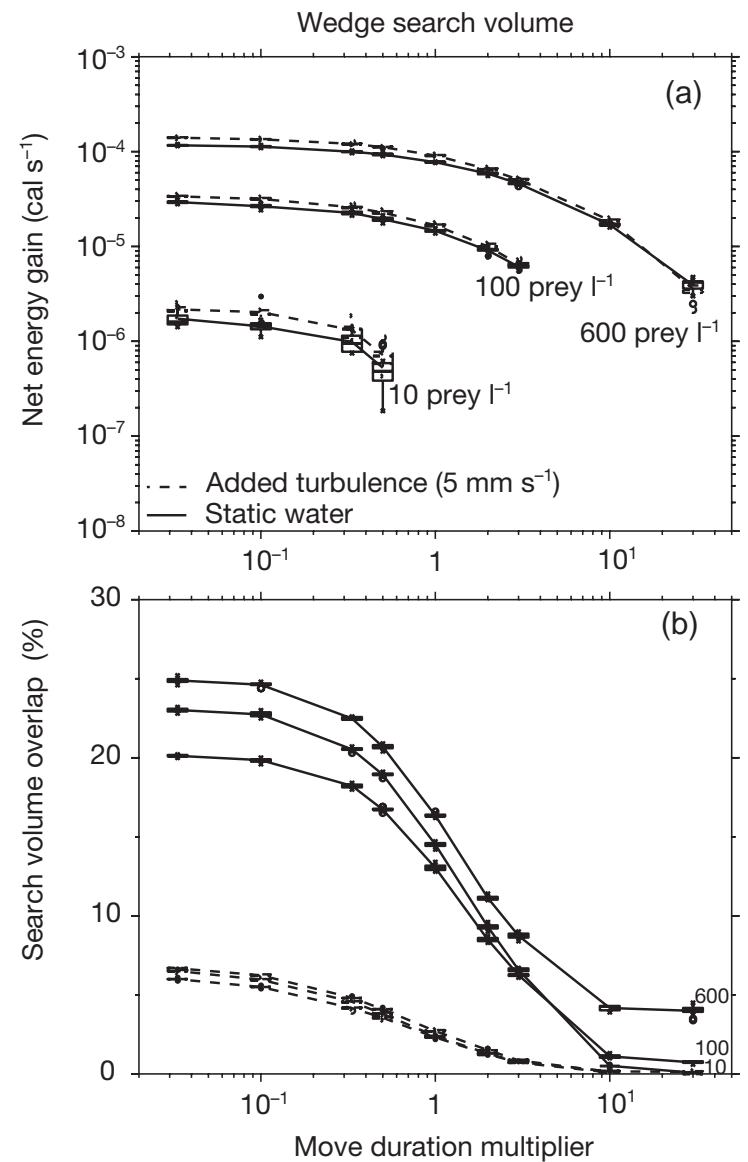

Fig. 6. Gadus morhua. (a) Net energy gain and (b) search volume overlap for $28 \mathrm{~d}$ post-hatch Atlantic cod larvae foraging on Calanus finmarchicus nauplii at 3 concentrations, with a wedge-shaped search volume. The horizontal axis is the multiplication factor applied to the static water move duration FD, from $1 / 30$ as long to 30 times longer. Lines are the means for 10 , 100 and 600 prey $^{-1}$ in both cases of static water (solid lines) as well as with $5 \mathrm{~mm} \mathrm{~s}^{-1}$ turbulent velocity added (dashed lines). Only positive values are shown, cutting off negative values of NEG at high move duration multipliers 
rotation of the predator is needed (without any forward motion) to yield a small search volume overlap, contrary to the case for a spherical search volume.

- Turbulence has less effect on NEG for a wedgeshaped search volume shape than it does when other shapes are used. This is because turbulence is not required for the predator to obtain a fresh search volume at each pause-travel iteration. A small rotation of the predator suffices. In static water, the search volume overlap is approximately $15 \%$ when movements are modelled by the observed FDs ( $x=1$ on Fig. 6 ), but only increases to approximately $25 \%$ if move duration is near zero. Thus, this factor should only be important to larvae when prey concentrations are low; conditions under which any small advantage would be important.

- The NEG levels are much lower for a given prey concentration than when using a spherical or hemispherical search volume. This is because the probability of finding a prey is much lower since only a small fraction $(1 / 23)$ of the volume of a sphere is searched. In fact, at low prey concentration $\left(10 \mathrm{l}^{-1}\right)$, the static water move duration observations (at $x=1$ in the figures) lead to model results with negative NEG. NEG only becomes positive when move durations are considerably reduced.

With respect to the last point, the observed FDs for the lowest prey concentration (Fig. 1) show a slight change in behaviour towards lower move durations relative to those exhibited at the higher prey concentrations. It would be interesting to conduct an experiment at even lower prey concentrations in order to determine if fish larvae move for shorter durations to keep their NEG positive in a manner that is consistent with the model predictions (assuming that our modelled energy costs are somewhat too high and that NEG isn't really negative in the laboratory setting at 10 prey $\mathrm{l}^{-1}$ ).

\section{Move speed}

Modulations in the movement pattern associated prey search (whether induced by turbulence or not) are not limited to the move duration. Chamorro (2001) observed that the mean move speed of fish larvae increased by a factor of 2 in the presence of turbulence, peaking at values of turbulent velocity between 2 and $12 \mathrm{~mm} \mathrm{~s}^{-1}$, depending upon the species. In this section, predator move speed FDs are modified in a manner analogous to that applied to move duration: by multiplying the abscissa in the static water move speed FDs of Fig. 1 by a constant ranging between $1 / 30$ and 30 . The highest increases in swim speed are unrealistic in light of findings by Chamorro (2001), but decreases to near-zero are certainly possible as it is conceivable that predators might stop swimming in strong turbulence.
Spherical search volume

The output of the model runs made with varying move speed and a spherical search volume are shown in Fig. 7. NEG decreases significantly for slow move speeds $(x<1)$ in static water, in a manner similar to that for move durations (Fig. 4). This is, again, due to an increase in search volume overlap between successive moves. As was the case for move durations, this decrease disappears with the addition of simulated turbulence.

There is little or no indication of a dome shape (as was found in Fig. 4) that would indicate a decrease in NEG at high move speeds $(x>1)$. A simple energy budgeting shows why. Firstly, basal energy costs are not significant relative to the normal cost of

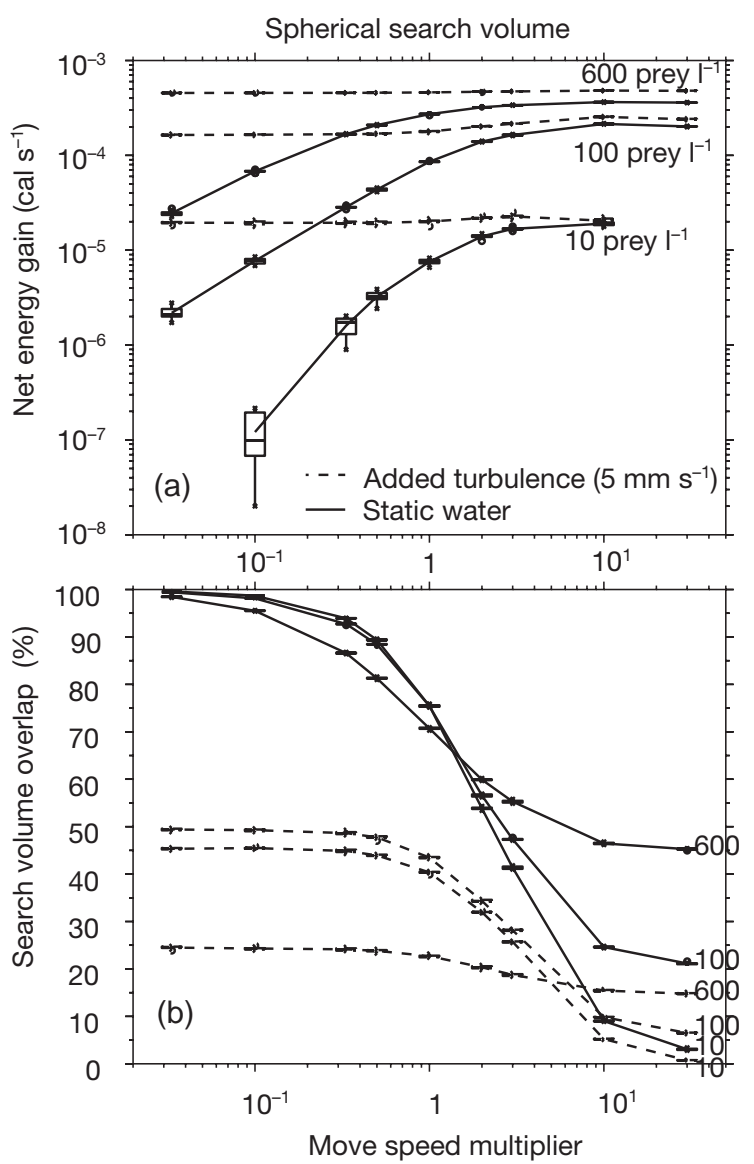

Fig. 7. Gadus morhua. (a) Net energy gain and (b) search volume overlap for $28 \mathrm{~d}$ post-hatch Atlantic cod larvae foraging on Calanus finmarchicus nauplii at 3 concentrations, with a spherical shaped search volume. The horizontal axis is the multiplication factor applied to the move speed FD, from $1 / 30$ as long to 30 times longer than normal. Lines are the means for 10, 100 and 600 prey l $1^{-1}$ in both cases of static water (solid lines) as well as with $5 \mathrm{~mm} \mathrm{~s}^{-1}$ turbulent velocity added (dashed lines) 
moves. The cost of moving begins to exceed the basal energy cost at the low mean move speed of $0.4 \mathrm{~mm} \mathrm{~s}^{-1}$. If the predator is moving a third of the time, that still only corresponds to a mean value of $1.2 \mathrm{~mm} \mathrm{~s}^{-1}$, which is slower than the typical lower bound of recorded move speeds as per Fig. 1. The mean move speed in Fig. 1 varies between 6.3 and $6.6 \mathrm{~mm} \mathrm{~s}^{-1}$, depending upon prey concentration. Thus, a predator that moves for a third of the time at this speed $\left(6.45 \mathrm{~mm} \mathrm{~s}^{-1}\right)$, and pauses for the remainder, will consume $1.46 \times 10^{-6} \mathrm{cal} \mathrm{s}^{-1}(15 \%$ from basal costs) but will only need to catch one prey every $22.5 \mathrm{~min}$ to maintain a positive energy balance. However, at the high prey concentration of 600 prey $\mathrm{l}^{-1}$, and with a spherical search volume (the largest of the 3), the model predicts prey captures every $7.2 \mathrm{~s}$ at normal swim speeds. Increasing the move speed multiplier to as much as 30 increases the energy requirements 30 -fold (to the equivalent of 1 capture every $45 \mathrm{~s}$ ), but reduces the search volume overlap sufficiently to increase the prey capture rate to once every $5.3 \mathrm{~s}$. This more than offsets the increased demand on energy consumption in the model. Using this model, and the incorrect assumption of a spherical search volume, one easily arrives at the erroneous conclusion that predators are at an energy balance advantage by moving as fast as they can while in static water in order to reduce search volume overlap. The introduction of turbulence negates this effect, reducing the overlap for all swimming (move) speeds.

\section{Hemispherical search volume}

The NEG results using a hemispherical search volume are presented in Fig. 8. Recall that in the case in which move duration was skewed, the dome shape that was observed using the spherical shape and static water (Fig. 4a, solid lines) disappeared using a hemisphere search volume shape (Fig. 5a, solid lines). Here, the same flattening of the NEG response occurs when changing the search shape from a sphere (Fig. 7a, solid lines) to a hemisphere (Fig. 8a, solid lines).

As for the spherical search volume, predators enhance NEG by moving faster in order to reduce search volume overlap. However, this generality does not hold at low prey concentration, at which the highest NEG occurs at the static water speed FD $(x=1)$ because the increase in energy consumption at higher speeds is not compensated for by the additional prey capture rate. Once again, the introduction of turbulence masks or reduces the influence of swim speed.
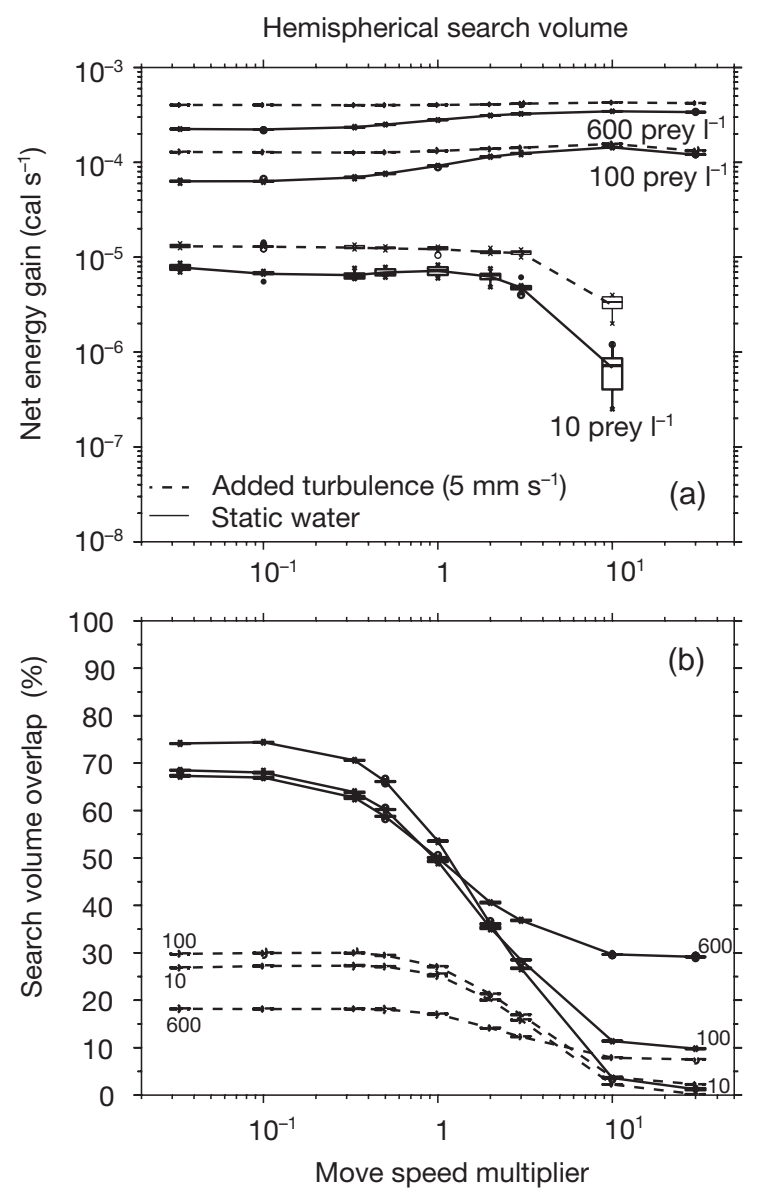

Fig. 8. Gadus morhua. (a) Net energy gain and (b) search volume overlap for $28 \mathrm{~d}$ post-hatch Atlantic cod larvae foraging on Calanus finmarchicus nauplii at 3 concentrations, with a hemispherical shaped search volume. The horizontal axis is the multiplication factor applied to the move speed FD, from $1 / 30$ as long to 30 times longer than normal. Lines are the means for 10, 100 and 600 prey $\mathrm{l}^{-1}$ in both cases of static water (solid lines) as well as with $5 \mathrm{~mm} \mathrm{~s}^{-1}$ turbulent velocity added (dashed lines)

\section{Wedge-shaped search volume}

Fig. 9 shows model results for the wedge shape. At high prey concentrations (600 prey $\mathrm{l}^{-1}$ ), only small gains are made at higher move speeds in the absence of turbulence, but these are flattened out when turbulence is added. The effect of turbulence is much smaller than when the other shapes are used, and the gains obtained from turbulence are greatest for decreases in move velocity $(x<1$ in Fig. 8). Fig. 9 cannot explain Chamorro's (2001) observation that move speeds increase in the presence of turbulence (before declining at very high levels) at prey concentrations of 10 prey $\mathrm{l}^{-1}$, except to say that turbulence makes survival possible at slightly higher move speeds. 

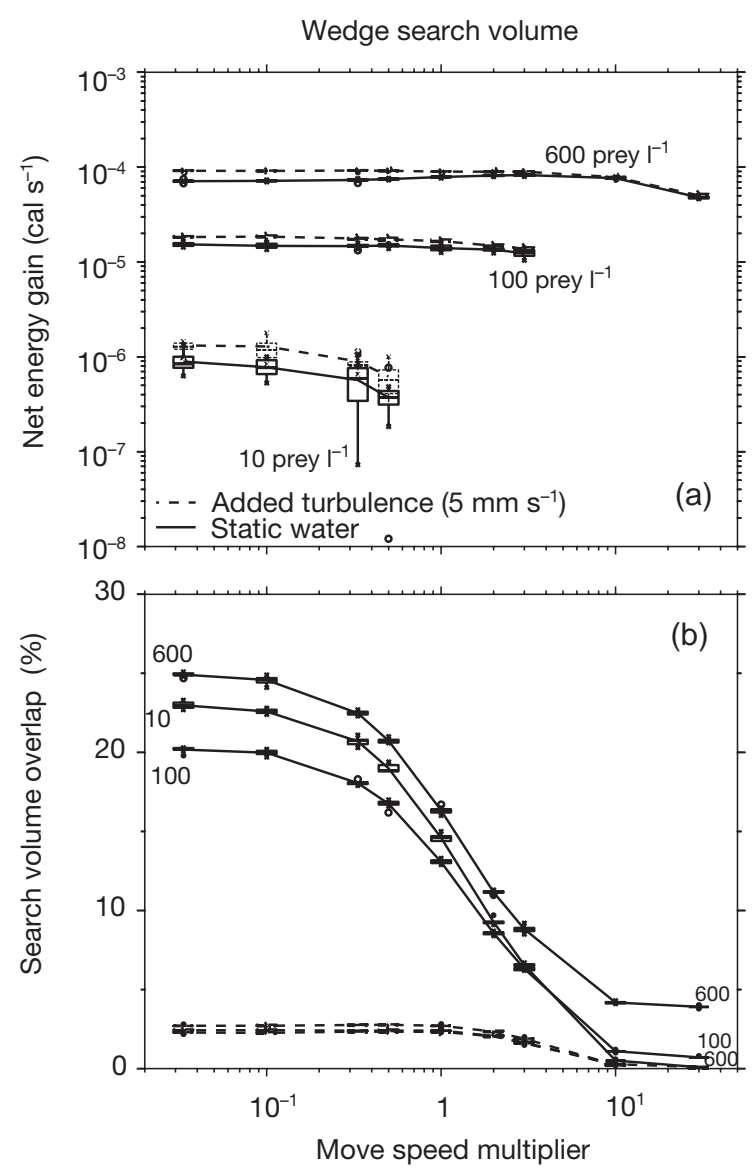

Fig. 9. Gadus morhua. (a) Net energy gain and (b) search volume overlap for $28 \mathrm{~d}$ post-hatch Atlantic cod larvae foraging on Calanus finmarchicus nauplii at 3 concentrations, with a wedge-shaped search volume. The horizontal axis is the multiplication factor applied to the move speed FD, from $1 / 30$ as long to 30 times longer than normal. Lines are the means for 10,100 and 600 prey $^{-1}$ in both cases of static water (solid lines) as well as with $5 \mathrm{~mm} \mathrm{~s}^{-1}$ turbulent velocity added (dashed lines)

At low prey concentration, predators with a wedgeshaped search volume cannot afford the energy expenditure of moving much faster than they already do (in stark contrast to what is predicted for a spherical search volume). At higher prey concentrations, on the other hand, the model shows that move speed could be 10 times faster (although physically impossible for the fish larvae) and still not be an energetically limiting factor. As discussed above, the energy used for motion is easily compensated for by a slight increase in the rate of prey capture.

The above indicates that either move speed is a limiting factor for fish larvae at low prey concentration, or that our parameterisation of the energy consumption is grossly incorrect. That parameterisation is based upon empirical work by von Herbing \& Boutilier (1996) which, as previously noted, is tentative. In their NEG model, Pitchford et al. (2003) used Stokes' Law to estimate the energy cost of motion. Stokes' Law implies a proportionality to the square of the move speed, instead of the linear proportionality reported by von Herbing \& Boutilier (1996), and applied here. This could indicate that the energy costs of swimming applied in the model are underestimates at higher velocities, which is probably true at the upper end of the move speed multipliers used in the model runs (which are, in any case, unrealistic). However, the von Herbing \& Boutilier (1996) energy cost of motion is always much higher than what is predicted by Stokes' Law. This implies that the physiological overhead is much greater than the viscous drag associated with moving through fluids at low Reynolds number. It is, therefore, unclear how far the von Herbing \& Boutilier (1996) estimate of the energy cost of motion can be extrapolated upwards. However, the correct estimate is clearly not found by direct application of Stokes' Law, which produces values that are much too low because it does not include physiological overhead. This, in any case, is largely academic since fish larvae are not likely to swim 10 times faster than their mean speeds (and certainly not while searching for prey). Within the bounds of feasible parametric values, the NEG model suggests that increased move speeds are an energetically limiting factor (only) at low prey concentrations, and that turbulence provides a small, but possibly important, gain ( 15 to $20 \%$ increase in prey encounters) at normal move speeds $(x=1)$. Gains are also observed at decreased move speeds $(x<1)$ at 10 prey $\mathrm{l}^{-1}$.

The observations of Chamorro (2001) are used to put our results into context. Fig. 10 shows the relationship between the swim speed of $10 \mathrm{~mm}$ long fathead minnow Pimephales promelas larvae and turbulent velocity (Chamorro 2001). These move speeds are much

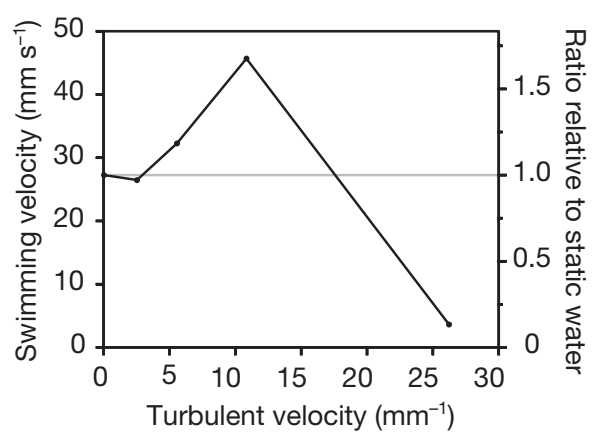

Fig. 10. Pimephales promelas. Relationship between the mean total swimming velocity of fathead minnow (of approximately $10 \mathrm{~mm}$ TL) and turbulence velocity. Adapted from Chamorro (2001) 
greater than those observed for cod larvae (Fig. 1), probably because the latter were smaller $(6 \mathrm{~mm})$, and our experimental temperature was much lower (6 vs. $25^{\circ} \mathrm{C}$ ). For that reason, we used the ratio of the swimming speed relative to static water measurements and applied that correction to the FD shown in Fig. 1 in additional model runs.

Fig. 11 shows the percent increase in NEG by cod larvae relative to static water conditions. The wedge shape at 10 prey $\mathrm{l}^{-1}$ is not shown because its NEG is negative, but the change in NEG for other shapes and prey concentrations are always positive. The increased move speed, which is maximal at a turbulent velocity of $10.8 \mathrm{~mm} \mathrm{~s}^{-1}$ (see Fig. 11), does not lead to a decrease in NEG due to higher energy expenditures associated with more swimming. However, the NEG predicted for a wedge-shaped search volume at the prey concentration of 100 prey $\mathrm{l}^{-1}$ exhibits a minimum at that turbulence level. In contrast, if the search volume were spherical, one would expect turbulence to increase NEG by as much as 75 to $300 \%$. Even the assumption of a hemispherical search volume yields modelled NEG increases of 50 to $100 \%$. This level of increase is consistent with the turbulence-related increases in prey ingestion rate predicted by earlier models, all of which are based upon spherical or hemispherical search space geometries (e.g. Kiørboe \& MacKenzie 1995, MacKenzie \& Kiørboe 1995, 2000, Fiksen \& MacKenzie 2002, Utne-Palm \& Stiansen 2002, Pitchford et al. 2003). Using the more realistic wedge shape yields increases that are typically less than $20 \%$.

\section{CONCLUSIONS}

For a pause-travel 28 d post-hatch cod larva with a wedge-shaped search volume, our model results demonstrate that the effect of turbulence on NEG through the reduction of successive search volume overlap is much smaller than when using a sphere or hemisphere search volume shape. Furthermore, the turbulence-related enhancements in prey captures are on the order of 15 to $20 \%$ for a wedge, as opposed to 50 to $150 \%$ for hemisphere and sphere. This is mainly because the overlap in successive search volumes is minimal to begin with when using a wedge, even in static water. In contrast to the case for a spherical search volume, with a wedge-shape only a small rotation of the predator is required to move it into a previously unsearched parcel of water. The possible negative effect of high levels of turbulence decreasing the ability of predators to catch prey is not considered in this analysis.

The factor that affects NEG the most is the prey concentration, since that variable can vary by a few orders

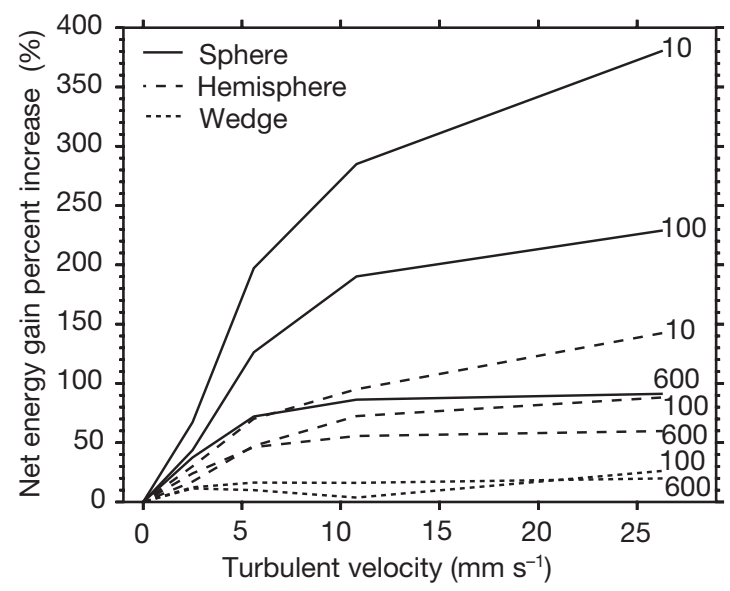

Fig. 11. Gadus morhua. Percent increase (relative to static water conditions) in the net energy gained by $28 \mathrm{~d}$ post-hatch Atlantic cod larvae foraging on Calanus finmarchicus nauplii at 3 concentrations, under various turbulent velocities, when the search volume is modelled as a sphere, a hemisphere or a wedge. For each turbulent intensity, the FD for move speed was adjusted according to Fig. 10

of magnitude and capture rates are proportional to it unless some value close to saturation is reached (e.g. the wedge shape used here requires a very high prey

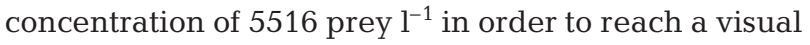
abundance $a$ of 1).

While enhancement from turbulence may still be important at the prey concentrations most likely encountered by fish larvae in the wild (and at which the larva's energy budget is on the edge of survivability), our results also imply that behavioural changes could lead to much more significant enhancements in NEG than those that could be associated with turbulence (under any realistic circumstances). Predator surroundings are not searched very efficiently by the wedge-shaped search volume because the larvae appear to move much more than required in order to search a fresh volume of water. A reduction in the time spent moving, and an increase in the percentage of time spent searching, would lead to much greater NEG than any turbulence-related increase. Observing fish larvae under turbulent conditions poses an enormous technical challenge. As a result, there has been almost no work on behaviour changes associated with turbulence. The one exception seems to be the study of Chamorro (2001), who observed turbulence related changes in swimming speed. Our model results indicate that changes in the time spent swimming, as opposed to searching, might be more important (at least for pause-travel searchers). It should be noted that if fish larvae spent less time moving and more time pausing and searching for prey, then effects that we have not considered here would gain in relevance, 
including the advection of prey into the search volume from turbulent strain during pauses. Further work on these behavioural issues is necessary.

While fish larvae and zooplankton both live in the world of the small scale, it is clear that they experience typical turbulence levels quite differently. The turbulent strain and rotation rates experienced by zooplankton are much more overwhelming than they are for fish larvae, which not only live at a slightly larger scale where turbulence is not quite as rotational, but are also possibly better able to compensate for these motions. Therefore, the approach and assumptions made in studying the effects of turbulence on fish larvae should, in general, not be applied to zooplankton. Further, the conclusions made for one of these organismal groups should not be freely transferred to the other.

Finally, as predicted by Browman \& Skiftesvik (1996), and Lewis (2003), the relationship between NEG and foraging behaviour, as well as the effect of turbulence on NEG, are greatly affected by search volume geometry. When a wedge-shaped search volume is applied, the advantage of turbulence is greatly reduced, although it could still be of importance to predators foraging at low prey concentrations. Following from this, it would be prudent to carefully reconsider the conclusions of any previous study that was based upon over-simplified search space geometries.

Acknowledgements. We are grateful to J. Runge for his support of the work. D. Fields made useful comments on an earlier draft of the manuscript as did D. Lewis on a later draft. We are grateful to the anonymous reviewers for valuable suggestions concerning the conclusions drawn from our results. This study was financed by the Department of Fisheries and Oceans Canada under 2 programs: 'Programme multidisciplinaire de recherche sur la morue du nord du golfe du SaintLaurent' (Maurice Lamontagne Institute), and 'Partitioning the total mortality of Atlantic cod stocks'. A.B.S's participation in this study constituted part of a sabbatical leave supported by the Institute of Marine Research, Norway (IMR). H.I.B's and A.B.S's continuing work on the early life history of fishes is supported by the IMR, and the Research Council of Norway.

\section{LITERATURE CITED}

Anderson JP, Stephens DW, Dunbar SR (1997) Saltatory search: A theoretical analysis. Behav Ecol 8:307-317

Browman HI (1996) Predator-prey interactions in the sea: commentaries on the role of turbulence. Mar Ecol Prog Ser 139:301-312

Browman HI, O'Brien WJ (1992a) Foraging and prey search behaviour of Golden Shiner (Notemigonus crysoleucas) larvae. Can J Fish Aquat Sci 49:813-819

Browman HI, O'Brien WJ (1992b) The ontogeny of search behavior in the white crappie, Pomoxis annularis. Environ Biol Fish 34:181-195

Browman HI, Skiftesvik AB (1996) The effects of turbulence on the predation cycle of fish larvae: comments on some of the issues. Mar Ecol Prog Ser 139:309- 312

Browman HI, Gordon WC, Evans BI, O'Brien WJ (1990) Correlation between historical and behavioral measures of visual acuity in a zooplanktivorous fish, the White Crappie, Pomoxis annularis. Brain Behav Evol 35:85-97

Browman HI, St-Pierre JF, Skiftesvik AB, Racca RG (2003) Behaviour of atlantic cod (Gadus morhua) larvae: an attempt to link maternal condition with larval quality. In: Browman HI, Skiftesvik AB (eds) The big fish bang. Proc 26th Annual Larval Fish Conference, 22-26 July 2002, Bergen. Institute of Marine Research, Bergen, p 71-95 (www.fishlarvae.com/book.asp?pg=52)

Chamorro VC (2001) The effects of small scale turbulence in the feeding ecology and swimming speed of fathead minnow larvae (Pimephales Promelas), inland silverside larvae (Menidia Beryllina) and the lobate ctenophore (Mnemiopsis Leidyi). MSc thesis, University of Maryland

Collins R, Tourtellot M, Bell W (1995) Defining stops in search pathways. J Neurosci Methods 60:95-98

Coughlin DJ, Strickler JR, Sanderson B (1992) Swimming behavior and search patterns in first feeding clownfish (Amphiprion perideraion) larvae. Anim Behav 44:427-44

Dower JF, Miller TJ, Leggett WC (1997) The role of microscale turbulence in the feeding ecology of larval fish. Adv Mar Biol 31:169-220

Fiksen Ø, MacKenzie BR (2002) Process-based models of feeding and prey selection in larval fish. Mar Ecol Prog Ser 243:151-164

Franks PJS (2001) Turbulence avoidance: an alternate explanation of turbulence enhanced ingestion rates in the field. Limnol Oceanogr 46:959-963

Gargett AE (1997) 'Theories' and techniques for observing turbulence in the ocean euphotic zone. Sci Mar 61 (Suppl 1):25-45

Hill PS, Nowell ARM, Jumars P (1992) Encounter rate by turbulent shear of particles similar in diameter to the kolmogorov scale. J Mar Res 50:643-668

Kiørboe T, MacKenzie BR (1995) Turbulence-enhanced prey encounter rates in larval fish: effects of spatial scale, larval behaviour and size. J Plankton Res 17:2319-2331

Kramer DL, McLaughlin RL (2001) The bahaviour ecology of intermittent locomotion. Am Zool 41:137-153

Lewis DM (2003) Planktonic encounter rates in homogeneous isotropic turbulence: the case of predators with limited fields of sensory perception. J Theor Biol 222:73-97

Maar M, Nielsen TG, Stips A, Visser AW (2003) Microscale distribution of zooplankton in relation to turbulent diffusion. Limnol Oceanogr 48:1312-1325

MacKenzie BR (2000) Turbulence, larval fish ecology and fisheries recruitement: a review of field studies. Oceanol Acta 23:357-375

MacKenzie BR (2002) Understanding the role of turbulence on fisheries production during the first century of ICES. ICES Mar Sci Symp 215:227-236

MacKenzie BR, Kiørboe T (1995) Encounter rates and swimming behaviour of pause-travel and cruise larval fish predators in calm and turbulent laboratory environments. Limnol Oceanogr 40:1278-1289

MacKenzie BR, Kiørboe T (2000) Larval fish feeding and turbulence: a case for the downside. Limnol Oceanogr 45: $1-10$

Munk P (1995) Foraging behaviour of larval cod (Gadus morhua) influenced by prey density and hunger. Mar Biol 122:205-212

Oakey NS, Elliot JA (1982) Dissipation within the surface mixed layer. J Phys Ocean 12:171-185 
O'BrienWJ, Browman HI, Evans BI (1990) Search strategies of foraging animals. Am Sci 78:152-160

O'Brien WJ, Evans BI, Browman HI (1989) Flexible search tactics and efficient foraging in saltatory searching animals. Oecologia 80:100-110

Pitchford JW, James A, Brindley J (2003) Optimal foraging in patchy turbulent environments. Mar Ecol Prog Ser 256: 99-110

Reiss CS, Anis A, Taggart CT, Dower JF, Ruddick B (2002) Relationaship among vertically structured in situ measures of turbulence, larval fish abundance and feeding sucess and copepods on Western Bank, Scotian Shelf. Fish Oceanogr 11:156-174

Rosenthal H (1969) Untersuchungen über das Beutefangverhalten bei Larven des Herings Clupea harengus. Mar Biol $3: 128-144$

Editorial responsibility: Otto Kinne (Editor),

Oldendorf/Luhe, Germany
Rosenthal H, Hempel G (1970) Experimental studies in feeding and food requirements of herring larvae (Clupea harengus L.). In: Steele JH (ed) Marine food chains. Oliver \& Boyd, Edinburgh, p 344-364

Rothschild BJ, Osborn TR (1988) Small-scale turbulence and plankton contact rates. J Plankton Res 10:465-474

Utne-Palm AC, Stiansen JE (2002) Effect of larval ontogeny, turbulence and light on prey attack rate and swimming activity in herring larvae. J Exp Mar Biol Ecol 268:147-170

von Herbing IH (2002) Effects of temperature on larval fish swimming performance: the importance of physics to physiology. J Fish Biol 61:865-876

von Herbing IH, Boutilier RG (1996) Activity and metabolism of larval Atlantic cod (Gadus morhua) from Scotian shelf and Newfoundland source populations. Mar Biol 124: 607-617

Submitted: February 6, 2004; Accepted: May 11, 2004

Proofs received from author(s): October 15, 2004 